\title{
Historis dan Ritualisme Tradisi Ziarah Makam Keleang Di Dusun Kelambi: Studi Terhadap Pendekatan Antropologi
}

\author{
Rohimi a, 1 \\ a Pascasarjana Interdisciplinary islamic studies UIN Sunan Kalijaga Yogyakarta \\ 1inobastian11@gmail.com
}

\begin{tabular}{|c|c|}
\hline Informasi artikel & ABSTRAK \\
\hline $\begin{array}{l}\text { Kata kunci: } \\
\text { Sejarah dan prosesi, ziarah } \\
\text { makam keleang, Tradisi } \\
\text { masyarakat, dan Dusun } \\
\text { Kelambi ogi }\end{array}$ & $\begin{array}{l}\text { Ziarah makam adalah salah satu bentuk budaya atau adat istiadat bagi } \\
\text { sebagian masyarakat di Indonesia. Dan ziarah makam, dilakukan dengan } \\
\text { mengunjungi makam wali, para ulama, dan juga makam keluarga. Dan } \\
\text { dalam penelitian ini bertujuan untuk mempelajari atau menganalisis } \\
\text { terkait dengan tradisi masyarakat Dusun Kelambi, Kecamatan Praya } \\
\text { Barat Daya, Lomok Tengah yang memiliki tradisi ziarah ke makam } \\
\text { Keleang. Penelitian ini menggunakan metode deskriptif kualitatif } \\
\text { fenomena yang terjadi pada kebiasaan yang telah diturunkan dari leluhur } \\
\text { masyarakat Dusun Kelambi terkait dengan ziarah ke makam Keleang. } \\
\text { Metode pengumpulan data dalam penelitian ini menggunakan metode } \\
\text { observasi dan wawancara dengan beberapa responden yang menjadi } \\
\text { sumber data. Hasil dan diskusi dalam penelitian ini. Pertama, terkait } \\
\text { dengan sejarah makam keleng, yang di klaim sebagai salah satu tempat } \\
\text { persinggahan atau tempat pertapaan wali Allah ketika menyebarkan } \\
\text { Islam di Lombok, dan di tempat itu salah satu dari wali tersebut } \\
\text { ketinggalan sorbannya atau selsendangnya, yang dalam bahasa sasak } \\
\text { selendang berarti "leang". Jadi itulah asal muasal nama makam keleang. } \\
\text { Kedua, kegiatan yang dilakukan oleh warga Dusun Kelambi saat } \\
\text { melakukan kunjungan ziarah ke makam Keleang, yaitu seperti } \\
\text { membakar timbung, membuat ketupat, menyemblih binatang, } \\
\text { mempersiapkan sesajen untuk acara dzikir dan do'a (roah), mencuci } \\
\text { muka dengan air ditambahkan ke tanah di dalam makam dan acara } \\
\text { terakhir yakni dzikir dan do'a. Dan masyarakat Dusun Kelambi } \\
\text { melakukan kunjungan ziarah ke makam sebanyak dua kali setahun yakni } \\
\text { di awal musim hujan dan kedua di awal musim panas atau musim } \\
\text { kemarau. }\end{array}$ \\
\hline
\end{tabular}

Keywords:

Historical Pilgrimage Tomb, keleang tomb, Community Tradition, and Kelambi Hamlet

\section{ABSTRACT}

The tomb pilgrimage is one of the forms of culture or customs for some people in Indonesia. And the tomb pilgrimage, carried out with a visit to the grave of the guardian, the scholars, and also the family tomb. And in this study aims to study or analyze related to the tradition of the people of Kelambi Hamlet, Praya Barat Daya District, Central Lomok who have a tradition of pilgrimage to the tomb of Keleang. This study uses descriptive qualitative methods of phenomena that occur in the habits that have been handed down from the ancestors of the Kelambi Hamlet community related to the pilgrimage to the tomb of Keleang. The method of data collection in this study used the method of observation and interviews with several respondents who became data sources. Results and discussion in this study. First, related to the history of keleng tombs, the story is said to be one of the places of stay or hermitage of Allah's guardian 
when spreading Islam in Lombok, and in that place one of the guardians missed a sling which in the language of sasak shawl means leang, so that is the origin of the name keleang tomb. Second, the activities carried out by the people of Kelambi Hamlet while making pilgrimages to the tomb of Keleang, namely burning the scales, making ketupat, preparing offerings, finally making dhikr and praying washing your face with water are added to the soil inside the tomb of Keleang. And the people of Kelambi Hamlet make a pilgrimage to the tomb of Keleang twice a year. first at the beginning of the rainy season and second at the beginning of summer or dry season.

\section{PENDAHULUAN}

Indonesia sebagai Negara yang sangat pluralisme terhadap suatu fanatisme, kebudayaan, dan adat istiadat. Oleh karena itu, indonesaia yang lahir sebagai Negara yang majemuk yang dilandasi dengan berbagai keragaman. Sebagai mana konstruksi kehiduapan masyarakat di Indonesia tidak akan bisa jauh dari budaya tersebut, sebagaimana indonesia dengan pemeluk agama islam terbesar di dunia, sehingga banyak kebudayaan yang lahir dengan beridentitas Islam. Misalnya budaya ziarah makam merupakan salah satu menjadi suatu bentuk budaya atau adat istiadat bagi masyarakat di Indonesia seperti melakukan kunjungan ziarah makam, yang dilakukan dengan berkunjung ke makam-makam wali, makam para ulama, dan juga makam keluarga. ${ }^{1}$

Kebudayaan mencakup semua hal yang dimiliki bersama oleh suatu masyarakat. Suatu kebudayaan mengandung semua pola kebiasaan-

${ }^{1}$ Syamhari, "Interpretasi Ziarah Pada Makam Mbah Periuk,” Jurnal Rihlah Vol. II No. 1 (2014). Hlm 28 kebiasaan suatu masyarakat, seperti dalam bidang ekonomi, religi, hukum, kesenian, dan lain sebagainya. Kebudayaan berarti tindakan yang dilakukan oleh masyarakat yang merupakan bentuk titipan dari nenek moyangnya yang harus dilestarikan dan dijagga. Karena bagi masyarakat sesuatu yang sifatnya turun temurun yang sudah kental menjadi praktik yang dilakukan oleh nenek moyangnya merupakan bentuk titipan yang harus tarsus dikerjakan sampai ke generasi, karena kebudayaan mengajarkan manusia untuk hidup selaras dengan alam, sekaligus memberikan tuntunan untuk berinteraksi dengan sesamanya. ${ }^{2}$

Karena jika kebudayaan ditinjau dari eksistensinya bagi manusia, kebudayaan memiliki tiga bentuk yakni sebagai suatu hasil yang dieksploitasi atas pikiran manusia, sebagai suatu aktifitas, dan berupa benda-benda. Ketiga wujud budaya tersebut mempunyai nilai-nilai yang

${ }^{2}$ Destien Mistavakia Sirait and Dasrun Hidayat, "Pola Komunikasi Pada Prosesi Mangulosi Dalam Pernikahan Budaya Adat Batak Toba," Jurnal Ilmu Komunikasi (J-IKA). Vol II. No.1 (April 2015), HIm 24. 
amat berharga bagi kehidupan. Dan sudah menjadi adat dan kebiasaan yang harus terus di tinjau dan dilakukan. Karena dalam adat merupakan praktik yang telah dilakukan oleh orang-orang sejarah yang sudah menjadi kebiasaan untuk terus dilakukan oleh generasi. ${ }^{3}$

Oleh karena itu, kunjungan ke makam orang yang telah meninggal dunia atau melakukan ziarah makam merupakan tradisi yang dilakukan sejak dulu oleh masyarakat, dan tindakan dalam membudayakan ziarah makam merupakan hasil atas pemikiran manusia itu sendiri, sehingga kebiasaan atau adat istiadat yang berkembang pada kehidupan masyarakat merupakan bentuk suatu tradisi yang harus dipraktikkan atau dilakukan sampai akhir zaman. Sejalan dengan penyebaran agama islam di Indonesia merupakan suatu bentuk kebudayaan yang harus dikembangkan dalam kehidupan masyarakat yang begitu kental, salah satunya tentang siarah makam. ${ }^{4}$ Dan ziarah makam ini dilakukan untuk menunjukkan kasih sayang terjadap orang yang telah meninggal dunia dan bertawasul kepada baginda Nabi Muhammad, para alim ulama, dan juga untuk para keluarga mereka, dengan melakukan zikir atau tahlilan,

${ }^{3}$ Abdiansyah Linge, "Entreprenuership Dalam Perspektif Alquran Dan Etnologi.," Jurnal Bisnis Dan Manajemen Islam Vol. 4, No. 2 (Desember 2016),. Hlm 12-13.

${ }^{4}$ Clifford Geertz, Abangan, Santri, Dan Priyai Dalam Masyarakat Jawa (Jakarta: Pustaka Jaya, 1998). Hlm 89. pembacaan ayat suci Al-Qur'an, dan mendoakan kebaikan. ${ }^{5}$

Salah satu tujunan dalam melakukan kegiatan ziarah makam yakni sebagai wadah untuk meminta doa kebaikan, dan untuk disampaikan doanya kepada Tuhan. Masyarakat mempercayai para penghuni kubur yang akan mewujudkan permintaan mereka karena menganggap mereka merupakan orang-orang shalih. ${ }^{6}$ Misalnya masyarakat melakukan ziarah makam ke makam wali, makam para ulama, seperti praktik ziarah makam yang dilakukan oleh masyarakat Dusun Kelambi di Lombok. Mereka melakukan itu semata-mata untuk melakukan doa dan meminta kebaikan lewat wali untuk disampaikan do'anya kepada Allah SWT.

Dalam penelitiannya saudari Hana Nurramah yang berjudul "Tradisi Ziarah Kubur Studi Kasus Perilaku Masyarakat Muslim Karawang yang Mempertahankan Tradisi Ziarah Pada Makam Syeh Quro di Kampung Pulo Bata Karawang tahun 1970-2013".7 Dalam penelitian ini menggunakan metode

5 Muthoharoh, "Tradisi Ziarah Makam Jum'at Kliwon," Skripsi UIN Sunan Kalijaga, 2009,. Hlm 3.

${ }^{6}$ Nabila Roshanbahar, "Konstruksi Sosial Ziarah Kubur Di Makam Gus Dur (Studi Di Makam Pondok Pesantren Tebuireng Kabupaten Jombang)," Jurnal Departemen Sosiologi Fakultas Ilmu Sosial Dan Ilmu Politik Universitas Airlangga, 2016.

${ }^{7}$ Hana Nurramah, "Tradisi Ziarah Kubur Studi Kasus Perilaku Masyarakat Muslim Karawang Yang Mempertahankan Tradisi Ziarah Pada Makam Syeh Quro Di Kampung Pulo Bata Karawang Tahun 1970-2013," Skripsi, Fakultas Adab Dan Humaniora Universitas Islam Negeri Syarif Hidayatullah Jakarta, 2014. 
pendekatan sosiologis dan antropologis. Bahwa menurut Hana tentang ziarah kubur yang dilakukan oleh masyarakat Karawang dan sekitarnya adalah kegiatan rutin dalam mendatangi makam orang-orang yang dianggap penting dan berjasa terutama terhadap orang yang dalam kehidupannya sudah menyebarkan agama Islam di Tatar Sunda khususnya Karawang, mendo'akan orang yang sudah meninggal, dengan tujuan beribadah untuk mendapatkan barokah serta mengingat tentang kematian dan akhirat.

Oleh karena itu ziarah makam sudah menjadi tradisi yang dipraktikkan oleh banyak kalangan masyarakat. Karena tradisi secara definisi berarti sesuatu yang dilakukan secara turun temurun yang pernah dipraktikkan dulu oleh nenek moyang. Sedangkan dalam bahasa latin, kata tradisi sering dikenal dengan "tradition" yang berarti diteruskan atau kebiasaan, dalam pengertian yang paling sederhana adalah sesuatu yang telah dilakukan untuk sejak lama dan menjadi bagian dari kehidupan suatu kelompok masyarakat. ${ }^{8}$

Sehingga tradisi ziarah makam sampai masa dewasa saat ini masih banyak kita lihat masyrakat yang melakukan ziarah makam. Karena Banyak masyarakat di daerah-daerah Indonesia yang melakukan ziarah ke tempat-tempat orang-orang sholeh atau seorang wali. Karena Dalam perspektif masyarakat bahwa wali

${ }^{8}$ Https://id.wikipedia.org/wiki/Tradisi,. akses tanggal 15 April 2019. merupakan orang yang dianggap dekat dan bersahabat dengan Allah, sehingga dengan tujuan masyarakat melakukan ziarah makam untuk menyampaikan doa mereka lewat wali untuk disampaikan kepada Allah. ${ }^{9}$ Dan beberapa hal yang wajib dilakukan ketika melakukan ziarah makam misalnya Membacakan AlQur'an yakni Surat Al-Fatihah, surat Al-Ikhlas, Surat AlFalaq, Surat AnNass, Surat Al-Baqarah, dan ayat Kursi, Berzikir dan bershalawat kepada Nabi Muhammad SAW, Istighfar kepada Allah SWT, dan Berdo'a dengan niat dan tujuan masing-masing. ${ }^{10}$

Oleh karena itu, masyarakat di Dusun Kelambi, salah satu Dusun yang berada di Desa Pandan indah Kecamatan Praya Barat Daya Lombok tengah, yang memiliki tradisi kunjungan ziarah makam disalah salah satu tempat yang dianggap sakral yang di klaim pernah disinggahi oleh wali Allah saat menyebar agama islam dulu di Lombok. Akan tetapi nama makam itu hanya penyebutan secara semiotik dari nenek moyang masyarakat pada zaman dahulu, karena kono ceritanya di tempat itu menjadi tempat persinggahan atau pertapaan wali allah dan salah satu dari wali tersebut ketinggalan selendangnya yang dalam bahasa sasak Lombok selendang itu dengan sebutan leang. Oleh karena

${ }^{9}$ Lukman Hakim, “Tradisi Ziarah Dan Ketenangan Jiwa” Skripsi: UIN Walisongo, 2017. Hlm 33

${ }^{10}$ Muhammad Tholhah Hasan, Ahlussunnah Wal-Jama'ah: Dalam Persepsi Dan Tradisi NU (Jakarta: Lantabora Press - Jakarta Indonesia, 2005). Hlm 237-238 
itu, masyarakat Dusun Kelambi menyebutnya dengan nama makam keleang. Akan tetapi makam keleang tersebut tidak hanya dikunjungi oleh masyarakat Dusun Kelambi, namun beberapa desa disekitar makam kelang itu juga melakukan kunjungan ziarah seperti desa Kabul, desa Ungge, desa Darek, dan Desa Mantokan. Dan disetiap desa memiliki tokoh yang menjadi pemimpin saat melakukan kunjungan ziarah ke makam keleang tersebut, misalnya masyarakat Dusun Kelambi di saat melakukan kunjungan ziarah ke makam keleang dipimpin oleh Bapak Mulasim.

\section{METODE PENELITIAN}

Penelitian ini berlokasi di Dusun Kelambi, Desa Pandan Indah Lombok Tengah NTB. Dan proses pengambilan data melalui metode observasi dan wawancara mendalam dengan beberapa masyarakat di Dusun Kelambi, dan juga sebagai Responden dalam penelitian ini untuk membantu memberikan informasi terkait dengan sejarah dan proses pada tradisi ziarah makam keleang yang menjadi salah satu tradisi yang turun-temurun yang masih dipraktikkan oleh masyarakat Dusun Kelambi sampai masa dewasa saat ini. Dan penelitian ini menggunakan penelitian kualitatif deskriptif atas fenomena yang terjadi di masyarakat Dusun Kelambi, dimana masyarakatnya yang memiliki tradisi ziarah ke makam keleang yang di klaim sebagai tempat persinggahan atau pertapaan wali Allah pada saat menyebarkan agama Islam di Lombok. Sehingga nama keleang itu berasal dari bahasa Lombok yakni "leang" artinya sebuah selendang dalam bahasa Indonesia, karena menurut manusia prasejarah, di tempat itulah salah satu dari wali Allah tersebut ketinggalan selendang atau sorbannya.

\section{HASIL DAN PEMBAHSAN}

Sejarah makam keleang dalam perspektif masyarakat Dusun Kelambi Desa Pandan Indah

Menurut Abdiansyah (2016) Kebudayaan dapat ditinjau dari eksistensinya bagi manusia, kebudayaan memiliki tiga bentuk yakni sebagai suatu hasil yang dieksploitasi atas pikiran manusia, sebagai suatu aktifitas, dan berupa benda-benda. Ketiga wujud budaya tersebut mempunyai nilai-nilai yang amat berharga bagi kehidupan. Dan sudah menjadi adat dan kebiasaan yang harus terus di tinjau dan dilakukan. Karena dalam adat merupakan praktik yang telah dilakukan oleh orang-orang sejarah yang sudah menjadi kebiasaan untuk terus dilakukan oleh generasi.

Oleh karena itu, masyarakat Dusun Kelambi merupakan salah satu masyarakat yang memiliki tradisi yang unik bahkan belum begitu diketahui secara tranparansi eksistensinya oleh khalayak ramai, karena ziarah ke makakm keleang merupakan tradisi atau praktisasi yang sudah menjadi tradisi turun-temurun dari nenek moyang masyarakat Dusun Kelambi. Dan makam keleang ini menurut orang-orang dahulu merupakan tempat 
pertapaan atau persinggahan wali Allah, dimana nama keleang itu berasal dari kata "leang" yang artinya sebuah selendang. Makam keleang bukan hanya tempat dimana maysarakat melakukan ziarah untuk meminta do'a dan lain sebagainya. Akan tetapi makam keleang juga tempat masyarakat melakukan syukuran, selametan, dan sunatan seorang bayi.

Sehingga tradisi ziarah makam keleang ini tentu hasil dari aktifitas, hasil pemikiran orang-prang pada zaman dahulu kala. Sehingga sampai saat ini masih di praktikkan karena sudah menjadi kebiasaan yang turun temurun dari ribuan tahun yang lalu. Dan dalam suatu kebudayaan jika ditinjau dari sebuah benda-benda, tentu pada ziarah makam keleang juga merupakan bentuk tradisi turuntemurun yang merupakan tradisi ziarah makam keleang, dimana di dalam makam kelenag itu yang dikalim tepat selendang wali Allah ketinggalan, dan di dalam area makam keleang terdapat sebuah batu dan tanah yang sudah dianggap sakral karena sudah disinggahi oleh seorang Wali yang dekat dengan Allah SWT. Sehingga sampai saat ini praktik tradisi ziarah makam keleang masih terus dilestarian oleh masyarakat di Dusun Kelambi Desa Pandan Indah Kecamatan Praya Barat Daya Lombok Tengah.

Makam keleang menjadi salah satu pusat ziarah yang dilakukan oleh masyarakat Dusun Kelambi, dimana makam keleang tersebut sudah dianggap tempat yang sakral dan memberikan manfaat bagi masyarakat Dusun Kelambi. Oleh karena itu, kunjungan masyarakat untuk berziarah ke makam keleang ini dilakukan sebanyak dua kali/tahun. Pertama, ketika awal musim kemarau atau musim panas. Kedua, ketika awal musim hujan, dan kunjungan ziarah ke makam keleang ini hanya dilakukan pada hari kamis saja tidak boleh di hari lain.

Makam keleang ini merupakan salah satu tempat yang diklaim sebagai tempat persinggahan para wali Allah SWT saat menyebarkan agama Islam di Lombok. Dan di dalam makam keleang ini ada sebuah kuburan yang menurut orang-orang prasejarah, belum terlalu diketahui itu kuburannya siapa, akan tetapi oleh masyarakat terdahulu mengklaim tempat itu sudah sakral, karena sudah di singgahi oleh wali Allah SWT pada saat menyebarkan agama islam di Lombok. Oleh karena itu, ziarah makam keleang ini akan terus dilakukan oleh masyarakat Dusun Kelambi, karena sudah menjadi tradisi yang di turunkan dari nenek moyang, yang dimana makam keleang ini juga memiliki relasi dengan makam wali nyatoq $^{11}$ yang berada di Desa Sade

\footnotetext{
${ }^{11}$ Makam Wali Nyatok yang berada di Desa Rembitan, Kecamatan Pujut, Lombok Tengah. Berziarah kemakam Wali Nyatok merupakan tradisi orang sasak terutama di sekitaran Lombok tengah. Dari zaman dahulu samapai sekarang pengunjungan makam Wali Nyatok biasanya di lakukan pada hari rabo. Karena menurut nenek moyang kita bahwasanya Wali Nyatok mencurahkan berkah kepada semua masyarakat yang berkunjung. Masyarakat berziarah kemakam Wali Nyatok bertujuan untuk meminta do'a.
} 
Kecamatan Pujut Kabupaten Lombok tengah. Karena makam nyatoq itu, di kalim sebagai makam wali atau kuburan wali Allah SWT, sedangkan makam keleang hanya saja sebagai tempat wali Allah melakukan persinggahan, dan ditempat itulah salah satu dari mereka yang ketinggalan selendangnya, sehingga tempat itu disebutkan dengan nama makam keleang.

Karena eksistensi masyarakat Dusun Kelambi melakukan ziarah ke makam kelang itu sudah lama, bahkan dari sejak saya belum lahir kakek nenek saya dulu sudah melakukan ziarah ke makam keleang. Dan sampai sekarang masyarakat Dusun Kelambi terus melakukan ziarah ke makam keleang, karena sudah menjadi tradisi. Dan kunjungan ziarah ke makam keleang dilakukan dua kali setahun yakni pada awal musim panas atau kemarau dan pada awal musim hujan. Dan makam keleang hanya di kunjungi pada hari kamis, dan sekitar jam 6 pagi masyarakat sudah berangkat dari rumah untuk melakukan kunjungan ziarah ke makam keleang. Tapi untuk sekarang transportasinya sudah mulai mudah, karena sudah ada motor dan mobil, dulu orang-orang mereka melakukan perjalanan kaki dari rumah untuk sampai di makam keleang.

Masyarakat Dusun Kelambi pergi ziarah ke makam keleang itu sebanyak dua kali pertahun. Pertama, ketika

Lihat

http://tradisigumipaersasak.blogspot.com/201

7/12/makam-wali-nyatok.html.

Diakses

tanggal 16 Maret 2019 Jam 17.23 WITA. musim hujan atau bertepatan dengan musim padi. Kedua, pada musim kemarau sesudah lebaran Idul Adha sekitar pada bulan September. Dan dari pengalaman saya, dulu saya jalan kaki dari rumah sampai ke makam keleang. Dan walaupun hujan panas matahari, kita semua tetap pergi ziarah ke makam keleang, karena sudah menjadi tradisi turun temurun dari nenek moyang yang sudah dilakukan sejak berabad-abad yang lalu. Dan ketika pergi ziarah ke makam keleang, masyarakat membawakan makanan untuk isi sesajen. Misalnya pada saat pergi ziarah pada musim hujan, masyarakat membawa ketupat, ayam, telur, kangkung, nasi timbung dan lain-lain. Sedangkan, ketika melakukan ziarah ke makam keleang pada musim panas atau musim kemarau, semua masyarakt membakar timbung pada hari rabu dari siang sampai sore sebagai makakna khas pada tradisi ziarah ke makam kelang. ${ }^{12}$

\section{Bentuk-bentuk prosesi dalam tradisi ziarah makam keleang oleh masyarakat Dusun Kelambi}

Dalam melakukan ziarah ke makam keleang, masyarakat Dusun Kelambi melakukan berbagai macam kegiatan untuk menyempurnakan penziarahannya. Dan beberapa bentuk-bentuk kegiatan masyarakat Dusun Kelambi dalam melakukan kunjungan ziarah ke makam keleang yang di klaim sebagai tempat sakral karena telah dsinggahi oleh wali Allah oleh masyarakat Dusun Kelambi yakni:

${ }^{12}$ Manam, Wawancara, 16 maret 2019. 


\section{Membakar timbung ${ }^{13}$}

Timbung merupakan makanan khas pada acara ziarah ke makam keleang yang menjadi tradisi masyarakat Dusun Kelambi. Timbung merupakan makanan yang dibuat dengan cara memasukkan beras ke dalam bambu dan dibungkus dengan daun pisang, kemudian bambu itu dibakar selama beberapa jam, dipembakarannya dilakukan satu hari sebelum berangkat ziarah ke makam keleang, misalnya ziarah makam keleang itu dilakukan pada hari kamis, maka pembakaran timbung itu dilakukan pada hari rabu siang sekitar jam 2 sampai sore. Setelah itu timbung dibawa menggunakan karung ataupun diikat dengan menggunakan tali dengan masih didalam bambu tempat timbung itu di bakar. Dan setelah sampai di lokasi makam keleang, lalu timbung itu dikeluarkan dan di potong sebagai isi sesajen untuk acara zikir dan do'a.

2. Membuat ketupat

Selain timbung ketupat juga merupakan salah satu makanan yang wajib menjadi isi sesajen ketika masyarakat melakukan kunjungan ziarah ke makam keleang. Ketupat sama seperti proses timbung yang dibuat sebelum satu hari pergi ziarah ke makam keleang. setelah itu ketupat juga menjadi salah satu isi sesajen saat pergi kunjungan ziarah

${ }^{13}$ Timbung merupakan makanan yang dibuat dengan cara memasukkan beras ke dalam bambu dan dibungkus dengan daun pisang, kemudian bambu itu di bakar satu hari sebelum berangkat ziarah ke makam keleang. ke makam keleang yang dilakukan oleh masyarakat Dusun Kelambi.

3. Penyemblihan binatang atau (Begorok)

Penyemblihan binatang yakni seperti ayam, kambing, dan kerbau sudah menjadi bagian dari tradisi masyarakat Dusun Kelambi dalam melakukan ziarah ke makam keleang. Akan tetapi, dalam penyemblihan binatang pada acara ziarah ke makam keleang dilakukan dengan dua cara yakni Pertama, Menyemblih binatang di rumah sehari sebelum pergi berangkat kunjungan ziarah ke makam keleang, misalnya dipersiapkan pada hari rabu, karena mereka berangkat untuk ziarah ke makam keleang hanya dilakukan pada pagi hari kamis sekitar jam 5:30. Kedua, dilakukan dengan cara menyemblih binatang di makam keleang langsung. Karena makam keleang itu bertempat di tengahtengah bendungan, sehingga areanya cukup luas. Misalnya ketika pemukanya mengatakan penyemblihan ayam atau kambing dilakukakn di makam keleang, maka setiap masyarakat mematuhinya dengan membawakan pisau, serabut kelapa, dan kayu bakar dari rumah untuk pembakaran dan penyemblihan binanatang di makam keleang. Dan hal ini menjadi bentuk pekerjaan para laki-laki, sedangkan para perempuan mempersiapkan sesajen untuk acara zikir dan do'a. Karena pekerjaan ini sudah menjadi hal yang wajib dilakukan oleh masyarakat Dusun Kelambi untuk penyempurnakan 
penziarahannya pada ziarah makam keleang. ${ }^{14}$

4. Mempersiapkan sesajen untuk acara $(\text { Roah })^{15}$

Disetiap melakukan ritual atau kunjungan ke tempat sakral, mungkin setiap masyarakat wajib melakukan cara khas untuk hadir pada tempat sakral tersebut, begitu juga pada ziarah ke makam keleang yang dilakukan oleh masyarakat Dusun Kelambi. Mereka sebelum pergi ziarah ke makam keleang, terlebih dahulu sudah mempersiapkan sesajen yang harus dibawa, karena hari ziarah ke makam keleang yang dilakukan oleh masyarakat Dusun Kelambi yakni pada hari kamis. Dan sebelum berangkat ke makam keleang, mereka sudah mempersiapkan makanan untuk isi sesajen di makam keleang seperti timbung, ketupat, ayam, telur, kacang, kangkung, dan terakhir botol akua dengan berisi air putih yang dipergunakan untuk cuci muka seluruh penziarah, yang konon ceritanya mampu membersihkan hati, digunakan untuk menyirami tanaman agar tumbuh dan subur, dan ketika para penziarah mencuci muka harus

\footnotetext{
${ }^{14}$ Haji G, Wawancara, 18 Maret 2019.

${ }^{15}$ Roah merupakan acara zikir dan do'a yang acap kali disebut dalam bahasa sasak Lombok yaitu (Roah). Oleh karena itu, sebelum acara roah atau zikir dan do'a dimulai pada acara ziarah kubur di makam keleang, para perempuan atau ibu-ibu harus mempersiapkan berbagai macam jenis makanan sebagai sesajen dalam acara roah atau zikir dan do'a yang akan dilaksanakan oleh para lelaki yang dipimpin oleh salah seorang ustat atau kiyai.
}

disertai dengan niat dan do'a agar menjadi lebih baik dunia wal akherat.

5. Cuci muka atau (Beseraup) ${ }^{16}$

Cuci muka dengan air yang sudah dimasukkan tanah di makam keleang merupakan acara ritual seluruh masyarakat yang melakukan ziarah ke makam keleang baik itu laki-laki, perempuan, dan anak-anak. Seperti penjelasan di atas bahwa hanya pemukanya yang bisa masuk ke dalam dimana tempat yang dianggap sebagai tempat persinggahan para wali Allah tersebut. Setelah itu, pemukanya memasukkan botol yang berisi air yang dibawa oleh penziarah saat melakukan ziarah ke makam keleang, kemudian pemukanya memasukkan tanah makam kelang ke dalam air tersebut. Kemudian air itu digunakan untuk mencuci muka dengan berbaris rapi dan mencuci muka secara teratur satu persatu dari seluruh masyarakat yang melakukan ziarah, yang dimana penziarah laki-laki terlebih dahulu mencuci muka setelah itu para penziarah perempuan. Dan pada saat mencuci muka dengan air tersebut seluruh penziarah dengan mengucapkan do'a sesuai niat dan harapan masing-masing. Dan yang konon ceritanya air itu sudah sakral dan air tersebut harus disimpan oleh masyarakat didalam rumahnya untuk

\footnotetext{
${ }^{16}$ Beseraup merupakan sebutan dalam bahasa sasak Lombok cuci muka. Besaraup di dalam tradisi ziarah kubur ke makam keleang merupakan acara sebelum zukur dan do'a, yang dimana beseraup ini wajib dilakukan oleh seluruh masyarakat yang berkunjung ke ziarah makam keleang, dengan memberikan do'a sesuai niat dan harapan masing-masing setiap individu.
} 
menyirami tanaman, misalnya tanaman padi, kacang, dan kedelai agar tumbuh dengan subur, dan untuk mencuci muka ketika sakit agar penyakitnya sembuh.

6. Acara zikir dan do'a (Roah)

Zikir dan do'a merupakan ritual yang dilakukan saat melakukan ziarah ke makam keleang yang dilakukan oleh masyarakat Dusun Kelambi Desa Pandan Indah Kecamatan Praya Barat Daya Lombok Tengah. Karena tujuan dalam melakukan ziarah ke makam keleang, untuk meminta petunjuk Tuhan dan meminta do'a untuk kebaikan, keberkahan, kesehatan, dan murah rezki. Dan setelah semua masyarakat yang telah melakukan cuci muka, maka setiap laki-laki bersila dan melakukan zikir dengan dipimpin oleh salah seorang Ustat atau Tuan Guru. Setelah beberapa lama para penziarah melakuka zikir dan juga do'a, setelah itu setiap laki-laki makan sesajen yang sudah dipersiapkan oleh para penziarah perempuan dengan disertai uang sebagai shalawat agar acara ziarah ke makam keleang itu menjadi kegiatan ziarah yang baik dan memberikan manfaat bagi masyarakat.

\section{KESIMPULAN}

Ziarah makam merupakan bentuk tradisi atau adat istiadat yang di turunkan oleh nenek moyang. Ziarah merupakan kegiatan yang dilakukan untuk meminta do'a maupun untuk mendoakan orang yang sudah meninggal dunia. Begitu pula tradisi yang terjadi di masyarakat Dusun Kelambi, memiliki satu tradisi yang unik haitu melkukan kunjungan ziarah ke makam keleang, yang konon ceritanya makam keleang itu bukan sebuah makam atau kuburan akan tetapi tempat persinggahan atau pertapaan wali Allah dulu saat menyebarkan agama Islam di Lombok. Sehingga tempat itu di klaim sakral oleh nenek moyang masyarakat Dusun Kelambi, sehingga sampai saat ini tradisi kunjungan ziarah ke makam keleang masih diparaktikkan oleh masyarakat Dusun Kelambi, karena salah satu bentuk peninggalan dari nenek moyang. Dan kunjungan ziarah ke makam keleang itu hanya di lakukan pada hari kamis sajam, dan sebanyak dua kali pertahun. Pertama, awal musim hujan dan kedua awal musim panas atau musim kemarau, kemudian masyarakat ziarah ke makam keleang hanya dilakukan pada hari kamis saja. Dan beberapa kegiatan yang wajib dilakukan oleh masyarakat Dusun Kelambi saat melakukan ziarah ke makam keleang yakni membakar timbung, menyemblih binatang seperti ayam, kambing bahkan kerbau, membuat ketupat, menyemblih binatang (begorok), mempersiapkan sesajen, mencuci muka dengan air yang sudah di masukkan ke dalam makam keleang dan sudah dimasukkan tanah dari makam keleang, terakhir zikir dan do'a atau (roah). 


\section{DAFTAR PUSTAKA}

Geertz, Clifford. Abangan, Santri, Dan Priyai Dalam Masyarakat Jawa. Jakarta: Pustaka Jaya, 1998.

http://tradisigumipaersasak.blogspot.c om/2017/12/makam-walinyatok.html.

Https://id.wikipedia.org/wiki/Tradisi.

Hakim, Lukman. "Tradisi Ziarah Dan

Ketenangan Jiwa (), Hlm 33." Skripsi: UIN Walisongo, 2017.

Linge, Abdiansyah. "Entreprenuership

Dalam Perspektif Alquran Dan Etnologi." Jurnal Bisnis Dan Manajemen Islam Vol. 4, No. 2 (Desember 2016).

Mistavakia Sirait, Destien, and Dasrun

Hidayat. "Pola Komunikasi Pada Prosesi Mangulosi Dalam Pernikahan Budaya Adat Batak Toba." Jurnal Ilmu Komunikasi (J-IKA). Vol II. No.1 (April 2015).

Muthoharoh. "Tradisi Ziarah Makam Jum'at Kliwon." Skripsi UIN Sunan Kalijaga, 2009.

Nurramah, Hana. "Tradisi Ziarah Kubur Studi Kasus Perilaku Masyarakat Muslim Karawang Yang Mempertahankan Tradisi
Ziarah Pada Makam Syeh Quro Di Kampung Pulo Bata Karawang Tahun 19702013." Skripsi, Fakultas Adab Dan Humaniora Universitas Islam Negeri Syarif Hidayatullah Jakarta, 2014.

Roshanbahar, Nabila. "Konstruksi Sosial Ziarah Kubur Di Makam Gus Dur (Studi Di Makam Pondok Pesantren Tebuireng Kabupaten Jombang)." Jurnal Departemen Sosiologi Fakultas Ilmu Sosial Dan Ilmu Politik Universitas Airlangga, 2016.

Syamhari. "Interpretasi Ziarah Pada Makam Mbah Periuk.” Jurnal Rihlah Vol. II No. 1 (2014).

Tholhah Hasan, Muhammad. Ahlussunnah Wal-Jama'ah: Dalam Persepsi Dan Tradisi NU. Jakarta: Lantabora Press - Jakarta Indonesia, 2005.

Zuhdi, Harfin dkk. Lombok Mirah Sasak Adi Sejarah Sosial Islam Budaya Dan Politik Ekonomi Lombok. Jakarta: Imsak Press, 2011. 